\title{
ORIGINAL
}

\section{Effect of obesity on declining beta cell function after diagnosis of type 2 diabetes: a possible link suggested by cross-sectional analysis}

\author{
Yoshifumi Saisho ${ }^{1)}$, Kumiko Tanaka ${ }^{1)}$, Takayuki Abe ${ }^{2)}$, Akira Shimada ${ }^{3)}$, Toshihide Kawai ${ }^{1)}$ and \\ Hiroshi Itoh ${ }^{1)}$ \\ 1) Department of Internal Medicine, Keio University School of Medicine, Tokyo 160-8582, Japan \\ 2) Center for Clinical Research, Keio University School of Medicine, Tokyo 160-8582, Japan \\ 3) Department of Internal Medicine, Saiseikai Central Hospital, Tokyo 108-0073, Japan
}

\begin{abstract}
It has been reported that beta cell function progressively declines in patients with type 2 diabetes. The objective of this study was to assess the effect of obesity on declining beta cell function after diagnosis of type 2 diabetes. We conducted a cross-sectional study of 689 consecutive subjects with type 2 diabetes who were admitted to our hospital from 2000 to 2007. Fasting and postprandial serum C-peptide immunoreactivity (CPR) and urinary CPR levels had been measured during admission. The subjects were stratified according to BMI and time since diagnosis. CPR index was calculated as CPR $(\mathrm{ng} / \mathrm{mL}) /$ plasma glucose $(\mathrm{mg} / \mathrm{dL}) \times 100$. All CPR measurements were significantly higher in the 263 obese (BMI $\geq 25$ ) subjects compared to the 426 lean subjects (BMI $<25$ ). There was a significant negative correlation between CPR indices and duration of diabetes, suggesting a progressive decline in beta cell function after diagnosis of type 2 diabetes. However, this decline was more apparent in obese subjects (postprandial CPR index 0.059/year) compared to lean subjects (0.025/year). The significant difference in serum CPR indices between the lean and obese subjects was lost in subjects more than 10 years after diagnosis. In conclusion, our observations suggest that beta cell function shows a greater progressive decline in obese subjects than in lean subjects with type 2 diabetes. Treatment of obesity may be an important strategy to preserve beta cell function in patients with type 2 diabetes.
\end{abstract}

Key words: Type 2 diabetes, Beta cell function, C-peptide, Obesity

TYPE 2 DIABETES is characterized by beta cell dysfunction and insulin resistance [1, 2]. Recent studies have shown a deficit of beta cell mass in type 2 as well as type 1 diabetes [3-6], with emergence of the idea that beta cell dysfunction is the central pathophysiological mechanism of type 2 diabetes. Importantly, not only is there a beta cell deficit in patients with type 2 diabetes, but also this deficit has been shown to worsen with the duration of diabetes. The UK Prospective Diabetes Study (UKPDS) has shown that this progressive decline in beta cell function is associated with deterioration of blood glucose control irrespective of the treatment strategy [7]. Moreover, we and others have

Submitted Aug. 16, 2011; Accepted Nov. 25, 2011 as EJ11-0206 Released online in J-STAGE as advance publication Dec. 8, 2011

Correspondence to: Yoshifumi Saisho, M.D., Ph.D., Department of Internal Medicine, Keio University School of Medicine, 35 Shinanomachi, Shinjuku-ku, Tokyo 160-8582, Japan.

E-mail: ysaisho@z5.keio.jp recently shown that beta cell dysfunction is associated with postprandial glucose excursion $[8,9]$. Therefore, it is important to explore factors to prevent declining beta cell function in order to control hyperglycemia in subjects with type 2 diabetes.

Recently, Funakoshi et al. have reported that the duration of diabetes exposure and BMI are major determinants of beta cell function in Japanese patients with type 2 diabetes[10]. Although the duration of diabetes is negatively correlated and BMI is positively correlated with beta cell function measured by serum C-peptide immunoreactivity (CPR), they reported that the decline in beta cell function with duration of diabe-

Abbreviations: CPR, C-peptide immunoreactivity; JDS, Japan Diabetes Society; JNS, Japan Nephrology Society; eGFR, estimated glomerular filtration rate; TZD, thiazolidinedione; $\alpha$-GI, $\alpha$-glucosidase inhibitor; CAD, coronary artery disease; UKPDS, UK Prospective Diabetes Study; ADOPT, A Diabetes Outcome Progression Trial; HOMA, homeostasis model assessment 
tes was greater in obese subjects than in lean subjects. Their study suggests the possibility that obesity may accelerate the decline in beta cell function. Their finding, however, has not yet been confirmed in other studies. Therefore, by using our cohort with detailed information on CPR indices and medical information, we aimed to assess the effect of obesity on declining beta cell function in subjects with type 2 diabetes.

\section{Research Design and Methods}

\section{Subjects}

We conducted a retrospective study of 689 consecutive patients with type 2 diabetes who were admitted to our hospital from 2000 to 2007 (439 men and 250 women, age $63 \pm 13$ years (mean $\pm \mathrm{SD}$ ), duration of diabetes $12.5 \pm 10.0$ years, BMI $24.4 \pm 4.1 \mathrm{~kg} / \mathrm{m}^{2}$, Table 1). Most (>90\%) patients had been admitted to hospital because of poor glycemic control, and received basal- bolus insulin therapy during admission. The other reasons for admission included sick day, hypoglycemia or other comorbidity. We excluded subjects positive for GAD or IA-2 antibody. We also excluded subjects with renal failure defined as serum creatinine level $\geq 2 \mathrm{mg} /$ $\mathrm{dL}$, as renal insufficiency affects CPR level. Beta cell function may be transiently impaired by marked hyperglycemia, so-called glucose toxicity. It has been reported that the beta cell response to glucose is blunted above a plasma glucose level of $180 \mathrm{mg} / \mathrm{dL}[11]$. Therefore, subjects with fasting plasma glucose (FPG) level $\geq$ $200 \mathrm{mg} / \mathrm{dL}$ on the day of CPR measurement $(\sim 15 \%$ of our whole cohort) were also excluded. Before admission, $47.9 \%$ of subjects were treated with sulfonylureas (SU), $1.9 \%$ with glinides, $13.9 \%$ with biguanides (BG), 8.0\% with thiazolidinedione (TZD), 25.8\% with $\alpha$-glucosidase inhibitors ( $\alpha$-GI) and $18.3 \%$ with insulin (Table 1), and $30.0 \%$ were receiving no medication. The subjects were classified according to the presence

Table 1 Characteristics of subjects.

\begin{tabular}{|c|c|c|c|c|}
\hline & Total & Lean & Obese & $p$ \\
\hline $\mathrm{N}$ & 689 & 426 & 263 & - \\
\hline Male $(\%)$ & 63.7 & 65.3 & 61.2 & 0.29 \\
\hline Age (years) & $63 \pm 13$ & $65 \pm 11$ & $59 \pm 14$ & $<0.001$ \\
\hline Duration of diabetes (years) & $12.5 \pm 10.0$ & $13.4 \pm 10.2$ & $11.0 \pm 9.43$ & 0.002 \\
\hline Family history of diabetes (\%) & 49.5 & 52.1 & 45.3 & 0.08 \\
\hline BMI $\left(\mathrm{kg} / \mathrm{m}^{2}\right)$ & $24.4 \pm 4.1$ & $21.8 \pm 2.1$ & $28.4 \pm 3.2$ & $<0.001$ \\
\hline $\mathrm{HbA} 1 \mathrm{c}(\%)$ & $9.9 \pm 1.8$ & $9.9 \pm 1.9$ & $9.8 \pm 1.7$ & 0.25 \\
\hline eGFR (mL/min) & $71.7 \pm 25.1$ & $72.6 \pm 26.4$ & $70.1 \pm 22.9$ & 0.21 \\
\hline \multicolumn{5}{|l|}{ Medication before admission } \\
\hline Sulfonylurea (\%) & 47.9 & 51.4 & 42.2 & 0.02 \\
\hline Glinide $(\%)$ & 1.9 & 1.6 & 2.3 & 0.55 \\
\hline Biguanide (\%) & 13.9 & 10.8 & 19.0 & 0.004 \\
\hline TZD $(\%)$ & 8.0 & 7.3 & 9.1 & 0.39 \\
\hline$\alpha-G I(\%)$ & 25.8 & 27.7 & 22.8 & 0.15 \\
\hline Insulin (\%) & 18.3 & 16.0 & 22.1 & 0.05 \\
\hline \multicolumn{5}{|l|}{ Complications } \\
\hline Diabetic retinopathy (\%) & 39.8 & 42.3 & 35.7 & 0.09 \\
\hline Diabetic nephropathy (\%) & 38.9 & 37.6 & 41.1 & 0.36 \\
\hline Diabetic neuropathy (\%) & 57.9 & 59.2 & 55.9 & 0.40 \\
\hline CAD $(\%)$ & 19.5 & 19.0 & 20.2 & 0.71 \\
\hline Stroke $(\%)$ & 14.1 & 12.9 & 16.0 & 0.27 \\
\hline \multicolumn{5}{|l|}{ CPR indices } \\
\hline FPG (mg/dL) & $143 \pm 30$ & $140 \pm 31$ & $149 \pm 29$ & $<0.001$ \\
\hline Fasting CPR $(\mathrm{ng} / \mathrm{mL})$ & $1.71 \pm 1.00$ & $1.47 \pm 0.81$ & $2.09 \pm 1.16$ & $<0.001$ \\
\hline Fasting CPR index & $1.22 \pm 0.73$ & $1.08 \pm 0.61$ & $1.45 \pm 0.84$ & $<0.001$ \\
\hline Postprandial PG (mg/dL) & $233 \pm 62$ & $232 \pm 64$ & $235 \pm 59$ & 0.46 \\
\hline Postprandial CPR (ng/mL) & $4.23 \pm 2.54$ & $3.70 \pm 2.11$ & $5.09 \pm 2.91$ & $<0.001$ \\
\hline Postprandial CPR index & $1.93 \pm 1.33$ & $1.69 \pm 1.08$ & $2.31 \pm 1.58$ & $<0.001$ \\
\hline Urinary CPR ( $\mu \mathrm{g} /$ day $)$ & $63.1 \pm 50.3$ & $53.5 \pm 40.2$ & $78.2 \pm 60.2$ & $<0.001$ \\
\hline Urinary CPR index & $0.46 \pm 0.36$ & $0.40 \pm 0.29$ & $0.55 \pm 0.43$ & $<0.001$ \\
\hline
\end{tabular}

eGFR, estimated glomerular filtration rate; FPG, fasting plasma glucose; CPR, C-peptide immunoreactivity; TZD, thiazolidinedione, $\alpha$-GI, $\alpha$-glucosidase inhibitor; CAD, coronary artery disease. $p$ values: lean vs. obese. 
of obesity, which was defined as BMI $\geq 25$ (Table 1). BMI was calculated from height and weight at the time of admission (i.e. BMI $=$ weight $(\mathrm{kg}) /$ height $(\mathrm{m})^{2}$ ). The mean BMI of lean and obese subjects was $21.8 \pm$ 2.1 vs. $28.4 \pm 3.2$, respectively $(p<0.001)$. The obese subjects were younger, with shorter duration after diagnosis compared to the lean subjects. A larger number of obese subjects used BG but not SU before admission compared to lean subjects. Approximately $40 \%$ of subjects had diabetic retinopathy.

This study was conducted according to the principles expressed in the Declaration of Helsinki and was approved by the ethics review committee of Keio University School of Medicine, Tokyo, Japan.

\section{Measurements}

All measurements were performed by the Department of Laboratory Medicine, Keio University School of Medicine with routine automated laboratory methods as previously reported $[9,12]$. HbAlc was measured by HPLC and expressed as the international standard value; i.e. HbA1c (JDS) $+0.4 \%$, as defined by the Japan Diabetes Society (JDS) [13].

Plasma glucose and serum CPR levels were measured after overnight fasting and $2 \mathrm{~h}$ after breakfast during admission, usually within a few days after admission under basal-bolus insulin therapy using regular and NPH insulin. Insulin therapy was started at a dose of $0.2-0.3 \mathrm{U} / \mathrm{kg}$, and then titrated to achieve good glycemic control (FPG $<130 \mathrm{mg} / \mathrm{dL}$ and postprandial plasma glucose $<180 \mathrm{mg} / \mathrm{dL}$, respectively) without hypoglycemia according to the guidelines of the Japan Diabetes Society [14]. During basal-bolus insulin therapy, insulin secretagogues (SU and glinides) were discontinued, but insulin non-secretagogues (BG, TZD and $\alpha$-GI) were usually continued. All patients were receiving the ideal dietary calorie intake calculated from their ideal body weight (i.e. height $(\mathrm{m})^{2}$ × 22 × $25 \mathrm{kcal} / \mathrm{kg}$; carbohydrate $50-60 \%$, protein $15-20 \%$ and fat $20-25 \%$ based on a meal-exchange plan) when blood samples were obtained. Plasma glucose was measured by glucose oxidase method and CPR was measured by EIA (ST AIA-PACK C-Peptide, TOSOH, Tokyo). Coefficient of variance $(\mathrm{CV})$ of the within-run and between-day precision of CPR was $2.39 \%$ and $2.97 \%$, respectively. Fasting and postprandial CPR indices were calculated as follows: fasting or postprandial serum CPR $(\mathrm{ng} / \mathrm{mL})$ / fasting or postprandial plasma glucose $(\mathrm{mg} / \mathrm{dL})$ x 100 , respectively. In addition, $24 \mathrm{~h}$ urinary CPR was also measured within a few days after admission. Urinary $\mathrm{CPR}$ index was calculated as $24 \mathrm{~h}$ urinary $\mathrm{CPR}(\mu \mathrm{g} /$ day $)$ / FPG (mg/dL).

Estimated glomerular filtration rate (eGFR: $\mathrm{mL} /$ $\min / 1.73 \mathrm{~m}^{2}$ ) was calculated according to the Statement of the Japan Nephrology Society (JNS) as follows: 194 $\mathrm{x}$ serum creatinine $(\mathrm{mg} / \mathrm{dL})^{-0.194} \mathrm{x}$ age $(\text { years })^{-0.287}(\mathrm{x}$ 0.739 for women) $[15,16]$.

Diabetic complications were precisely evaluated during admission. Diagnosis of diabetic retinopathy was performed by ophthalmologists.

\section{Statistical analysis}

Descriptive statistics were calculated for the baseline characteristics. Comparisons between two groups were performed with Student's $t$-test or Fisher's exact test. Comparisons among three or more groups were performed with ANOVA followed by Scheffe's post hoc analysis. Correlations between two parameters adjusted for some confounding factors were performed with an ANOVA model. The difference in slopes of the CPR index against duration of diabetes between the lean and obese groups was examined with an ANOVA model that contained an interaction term between the duration and obesity. All statistical analyses were conducted using the Statistical Package for the Social Sciences (version 17.0; SPSS, Chicago, IL, USA). All data are expressed as mean \pm SD except those in Fig. 2 in which the data are expressed as mean $\pm \mathrm{SE}$, and $p<0.05$ (two-sided) was considered statistically significant.

\section{Results}

\section{Negative correlation between beta cell function and time after diagnosis}

CPR indices in lean and obese subjects are shown in Table 1. All CPR indices were greater in obese than in lean subjects (all $p<0.001$ ).

There were significant negative correlations between CPR indices and time after diagnosis among all the subjects (Fig. 1A-C), suggesting a progressive decline in beta cell function after diagnosis of type 2 diabetes. Among them, the strongest negative correlation with time after diagnosis was seen in postprandial CPR index ( $r=-0.297, p<0.001$, Fig. 1B and Table 2). This correlation remained significant after adjustment for sex, age, family history of diabetes, BMI, HbA1c, eGFR and medication for diabetes before admission ( $\beta$ $=-0.201, p<0.001$, Table 2). 

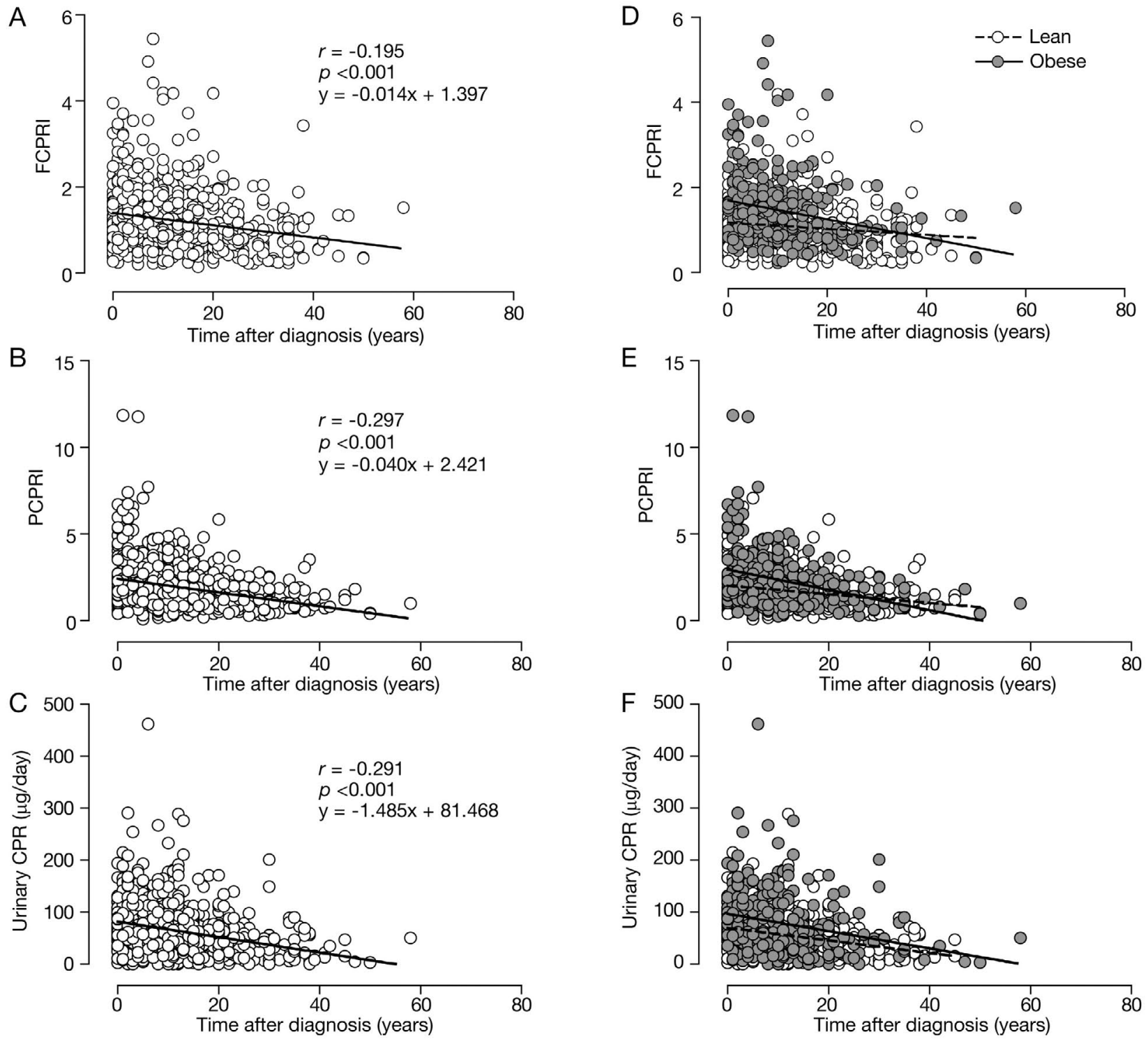

Fig. 1 Correlation between beta cell function and time after diagnosis. In all the subjects, fasting CPR index (FCPRI, A), postprandial CPR index (PCPRI, B) and urinary CPR (C) were significantly negatively correlated with time after diagnosis. D-F) This decline in beta cell function was greater in obese subjects than in lean subjects; D) $r=-0.121, p=0.01, \mathrm{y}=-0.007 \mathrm{x}+1.173$ in lean and $r$ $=-0.246, p<0.001, \mathrm{y}=-0.022 \mathrm{x}+1.693$ in obese, E) $r=-0.236, p<0.001, \mathrm{y}=-0.025 \mathrm{x}+2.026$ in lean and $r=-0.349, p<0.001, \mathrm{y}$ $=-0.059 \mathrm{x}+2.955$ in obese, F) $r=-0.302, p<0.001, \mathrm{y}=-1.209 \mathrm{x}+69.514$ in lean and $r=-0.260, p<0.001, \mathrm{y}=-1.660 \mathrm{x}+96.547$ in obese subjects.

\section{Effect of obesity on declining beta cell function}

When the subjects were divided into lean and obese subgroups, this decline in beta cell function was greater in obese subjects than in lean subjects (Fig. 1D-F), with an estimated decline in postprandial CPR index of $0.059 /$ year in obese subjects, versus $0.025 /$ year in lean subjects. The slopes of serum CPR indices against time after diagnosis were significantly different between lean and obese subjects $(p=0.009$ and 0.001 ; for interaction between fasting CPR index or postprandial CPR index and obesity, respectively), while the slope of urinary CPR against time after diagnosis was not $(p=0.24$; for interaction between urinary CPR and obesity).

To assess the correlation between beta cell function and time after diagnosis, the subjects were divided into quartiles according to the time after diagnosis $(0-4,5-10$, $11-17$ and $\geq 18$ years) and then further divided into lean and obese subgroups (Tables 3 and 4). In both lean and 
Table 2 Correlation between postprandial CPR index and time after diagnosis in simple and multiple regression analyses

\begin{tabular}{lccccc}
\hline & \multicolumn{2}{c}{ Simple regression } & & \multicolumn{2}{c}{ Multiple regression } \\
\cline { 2 - 3 } \cline { 5 - 6 } & \multicolumn{1}{c}{$r$} & $p$ & & $\beta$ & $p$ \\
\hline Sex (male/female) & 0.038 & 0.32 & & 0.055 & 0.10 \\
Age & -0.134 & $<0.001$ & & -0.078 & 0.07 \\
Time after diagnosis & -0.297 & $<0.001$ & & -0.201 & $<0.001$ \\
Family history of diabetes (yes/no) & -0.079 & 0.04 & & -0.019 & 0.57 \\
BMI & 0.329 & $<0.001$ & & 0.253 & $<0.001$ \\
HbA1c & -0.142 & $<0.001$ & & -0.233 & $<0.001$ \\
eGFR & -0.143 & $<0.001$ & & -0.208 & $<0.001$ \\
Sulfonylurea (yes/no) & -0.124 & $<0.001$ & & -0.178 & $<0.001$ \\
Glinide (yes/no) & 0.092 & 0.02 & & 0.048 & 0.15 \\
Biguanide (yes/no) & 0.008 & 0.84 & & -0.016 & 0.63 \\
TZD (yes/no) & -0.060 & 0.12 & & -0.050 & 0.13 \\
$\alpha-G I$ (yes/no) & -0.065 & 0.09 & & -0.025 & 0.48 \\
Insulin (yes/no) & -0.205 & $<0.001$ & & -0.272 & $<0.001$ \\
\hline
\end{tabular}

eGFR, estimated glomerular filtration rate; TZD, thiazolidinedione; $\alpha$-GI, $\alpha$-glucosidase inhibitor

Table 3 Characteristics of lean subjects according to time after diagnosis

\begin{tabular}{|c|c|c|c|c|c|}
\hline & \multicolumn{4}{|c|}{ Time after diagnosis (years) } & \multirow{2}{*}{$p$} \\
\hline & $0-4$ & $5-10$ & $11-17$ & $\geq 18$ & \\
\hline $\mathrm{N}$ & 93 & 106 & 104 & 123 & - \\
\hline Male (\%) & 67.7 & 64.2 & 60.6 & 68.3 & 0.61 \\
\hline Age (years) & $59 \pm 13$ & $64 \pm 11$ & $65 \pm 10$ & $71 \pm 9$ & $<0.001$ \\
\hline Time after diagnosis (years) & $1.3 \pm 1.3$ & $8.1 \pm 1.9$ & $14.1 \pm 1.9$ & $26.4 \pm 7.0$ & $<0.001$ \\
\hline Family history of diabetes (\%) & 39.8 & 51.9 & 58.7 & 56.1 & 0.04 \\
\hline BMI $\left(\mathrm{kg} / \mathrm{m}^{2}\right)$ & $22.1 \pm 2.4$ & $21.7 \pm 2.0$ & $22.0 \pm 2.0$ & $21.6 \pm 1.9$ & 0.29 \\
\hline HbAlc $(\%)$ & $11.2 \pm 2.1$ & $10.1 \pm 2.1$ & $9.4 \pm 1.4$ & $9.3 \pm 1.3$ & $<0.001$ \\
\hline eGFR (mL/min) & $81.6 \pm 26.8$ & $73.8 \pm 23.8$ & $72.3 \pm 26.6$ & $65.1 \pm 26.3$ & $<0.001$ \\
\hline \multicolumn{6}{|l|}{ Medication before admission } \\
\hline Sulfonylurea (\%) & 18.3 & 50.9 & 70.2 & 61.0 & $<0.001$ \\
\hline Glinide $(\%)$ & 2.2 & 4.7 & 0.0 & 0.0 & 0.02 \\
\hline Biguanide (\%) & 4.3 & 7.6 & 21.2 & 9.8 & 0.001 \\
\hline TZD $(\%)$ & 2.2 & 8.5 & 8.7 & 8.9 & 0.20 \\
\hline$\alpha$-GI (\%) & 7.5 & 20.8 & 39.4 & 39.0 & $<0.001$ \\
\hline Insulin (\%) & 3.2 & 11.3 & 14.4 & 30.9 & $<0.001$ \\
\hline \multicolumn{6}{|l|}{ Complications } \\
\hline Diabetic retinopathy (\%) & 23.7 & 35.9 & 46.2 & 58.5 & $<0.001$ \\
\hline Diabetic nephropathy (\%) & 24.7 & 34.9 & 35.6 & 51.2 & $<0.001$ \\
\hline Diabetic neuropathy (\%) & 41.9 & 57.6 & 67.3 & 66.7 & 0.001 \\
\hline $\mathrm{CAD}(\%)$ & 7.5 & 21.7 & 17.3 & 26.8 & 0.003 \\
\hline Stroke (\%) & 2.2 & 12.3 & 11.5 & 22.8 & $<0.001$ \\
\hline \multicolumn{6}{|l|}{ CPR indices } \\
\hline FPG $(\mathrm{mg} / \mathrm{dL})$ & $143 \pm 31$ & $143 \pm 32$ & $142 \pm 32$ & $132 \pm 27$ & 0.01 \\
\hline Fasting CPR (ng/mL) & $1.59 \pm 0.81$ & $1.53 \pm 0.86$ & $1.58 \pm 0.86$ & $1.22 \pm 0.66$ & 0.001 \\
\hline Fasting CPR index & $1.16 \pm 0.63$ & $1.08 \pm 0.59$ & $1.15 \pm 0.67$ & $0.94 \pm 0.53$ & 0.02 \\
\hline Postprandial PG (mg/dL) & $226 \pm 62$ & $237 \pm 69$ & $235 \pm 63$ & $229 \pm 62$ & 0.54 \\
\hline Postprandial CPR (ng/mL) & $4.38 \pm 2.33$ & $3.84 \pm 2.32$ & $3.71 \pm 1.90$ & $3.05 \pm 1.74$ & $<0.001$ \\
\hline Postprandial CPR index & $2.12 \pm 1.34$ & $1.72 \pm 1.11$ & $1.65 \pm 0.93$ & $1.38 \pm 0.83$ & $<0.001$ \\
\hline Urinary CPR ( $\mu \mathrm{g} /$ day) & $69.9 \pm 43.5$ & $58.8 \pm 39.3$ & $50.7 \pm 43.4$ & $38.6 \pm 28.1$ & $<0.001$ \\
\hline Urinary CPR index & $0.52 \pm 0.35$ & $0.42 \pm 0.28$ & $0.38 \pm 0.30$ & $0.30 \pm 0.21$ & $<0.001$ \\
\hline
\end{tabular}

eGFR, estimated glomerular filtration rate; FPG, fasting plasma glucose; CPR, C-peptide immunoreactivity; TZD, thiazolidinedione; $\alpha$-GI, $\alpha$-glucosidase inhibitor; CAD, coronary artery disease $p$ values: among the groups. 
Table 4 Characteristics of obese subjects according to time after diagnosis

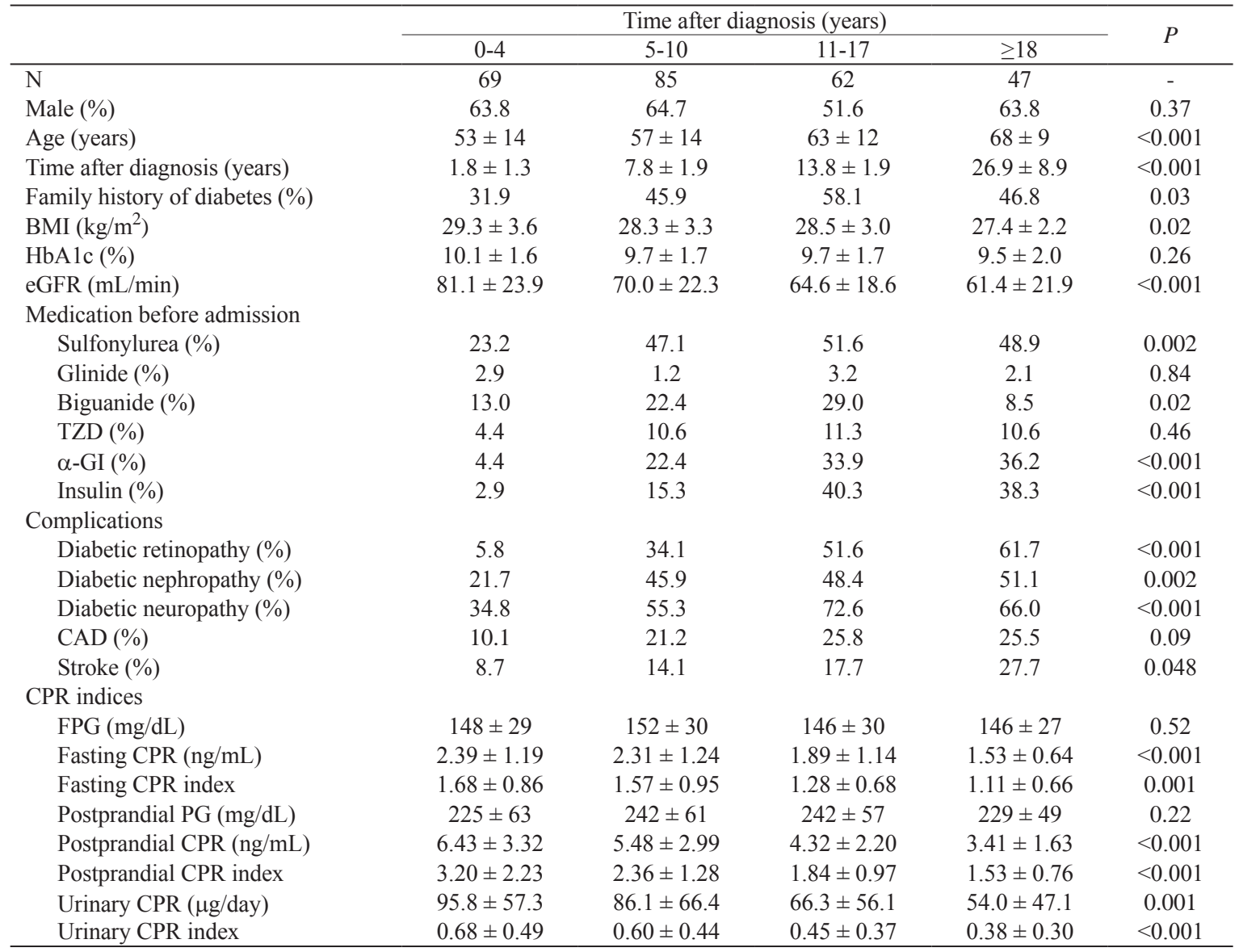

eGFR, estimated glomerular filtration rate; FPG, fasting plasma glucose; CPR, C-peptide immunoreactivity; TZD, thiazolidinedione; $\alpha$-GI, $\alpha$-glucosidase inhibitor; CAD, coronary artery disease $p$ values: among the groups

obese subjects, there was a significant increase in age, diabetic medication and complications, and a significant decrease in eGFR among the quartiles. There was a significant decrease among the quartiles in $\mathrm{HbAlc}$ in lean subjects and BMI in obese subjects. Comparisons of each CPR index classified by obesity and time after diagnosis are presented in Fig. 2. There were significant differences in CPR measurements between lean and obese subjects in the first and second quartiles of the time after diagnosis (all $p<0.05$ ), but no significant differences in fasting and postprandial CPR indices were observed in the third and fourth quartiles $(p=$ 0.24 and 0.22 in the third quartile, $p=0.08$ and 0.29 in the fourth quartile, respectively).

\section{Discussion}

In this cross-sectional study, 1) there was a signif- icant negative correlation between CPR indices and time after diagnosis in subjects with type 2 diabetes, and 2) this correlation was more apparent in obese subjects than in lean subjects.

Type 2 diabetes is characterized by beta cell dysfunction and insulin resistance $[1,2]$. It is widely recognized that type 2 diabetes is a progressive disease. UKPDS has shown that beta cell function measured by homeostasis model assessment (HOMA) in subjects with newly diagnosed type 2 diabetes was $\sim 50 \%$ of that in normal subjects and continued to decline at $\sim 5 \% /$ year [7]. UKPDS has also shown that glycemic control in those subjects gradually deteriorated with time irrespective of treatment, and this deterioration of glycemic control was mainly due to a decline in beta cell function [7]. The deterioration of glycemic control with time in subjects with type 2 diabetes in relation to declining beta cell dysfunction has been confirmed in 


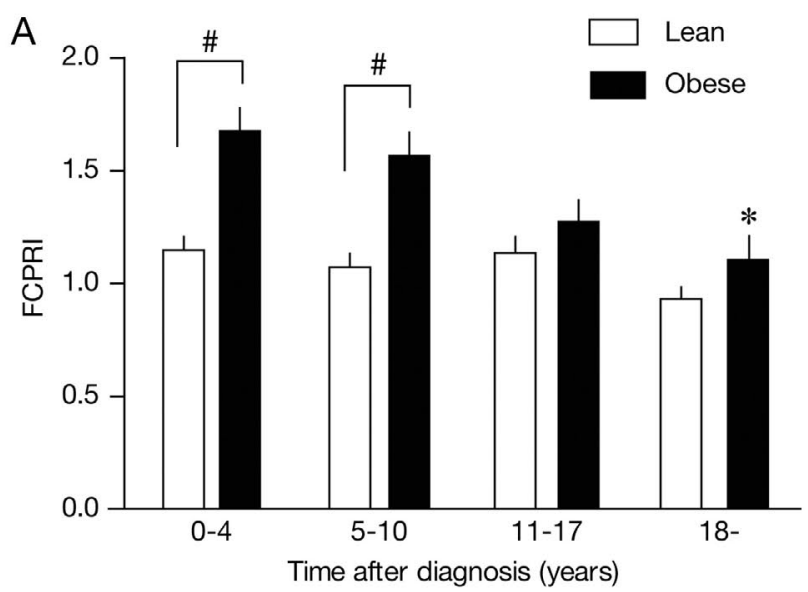

B
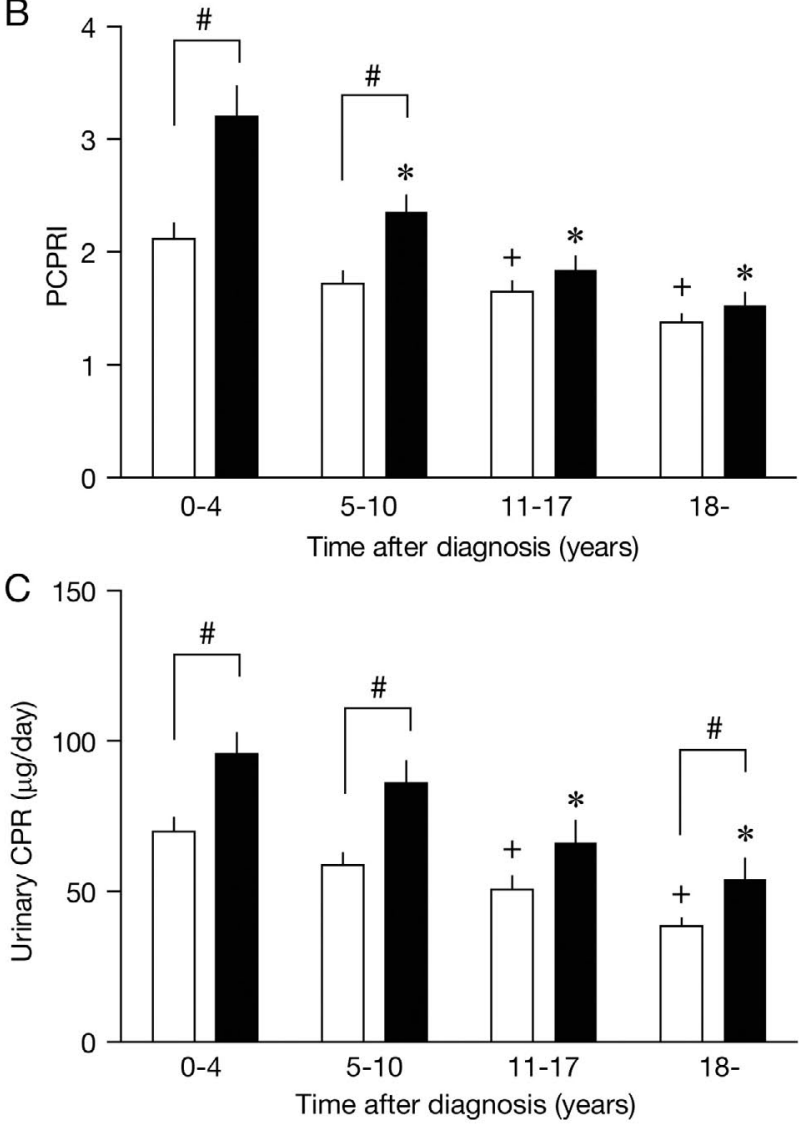

Fig. 2 CPR measurements in subjects according to obesity and time after diagnosis (0-4, 5-10, 11-17 and $\geq 18$ years); A) fasting CPR index (FCPRI), B) postprandial CPR index (PCPRI) and C) urinary CPR. There were significant differences in CPR measurements between lean and obese subjects in the first and second quartiles of time after diagnosis (all $p<0.05$ ), but no significant differences in fasting and postprandial CPR indices were observed in the third and fourth quartiles $(p=0.24$ and 0.22 in the third quartile, $p=0.08$ and 0.29 in the fourth quartile, respectively). ${ }^{*} p<0.05$ vs. obese subjects $\leq 4$ years after diagnosis, $+p<0.05$ vs. lean subjects $\leq 4$ years after diagnosis, $\# p<0.05$ vs. lean subjects.
A Diabetes Outcome Progression Trial (ADOPT) [17]. These results strongly suggest that recovery or preservation of beta cell function is an important therapeutic strategy for type 2 diabetes.

ADOPT showed that treatment with thiazolidinediones resulted in better glycemic control compared with SU, with better preservation of beta cell function [17]. However, the effect of other parameters such as obesity on declining beta cell function remains unknown. Recently, Funakoshi et al. have reported that BMI was positively correlated and duration of diabetes was negatively correlated with serum CPR level in subjects with type 2 diabetes [10]. They also pointed out that the decrease in CPR level with duration of diabetes was greater in obese subjects than in lean subjects, suggesting that obesity may accelerate the decline in beta cell function with time in subjects with type 2 diabetes. Although this is a very important finding that indicates that treatment of obesity may be an important therapeutic strategy to preserve beta cell function, this finding has not been confirmed in other studies. In the present study, using a cohort with a large sample size and detailed medical information, we were able to confirm that the decline in beta cell function with time was more apparent in obese subjects than in lean subjects. It should be noted that since the study by Funakoshi et al. and our study were crosssectional, interpretation of the results needs to be done very carefully. Nonetheless, our cohort with detailed medical information could strengthen our conclusion, while the previous study did not provide information on medication, which might affect beta cell function. In the present study, we confirmed that SU, which may worsen beta cell function, was more frequently used in lean subjects than in obese subjects. On the other hand, the use of TZD, which may preserve beta cell function, was comparable in lean and obese subjects, although it should be mentioned that the results of ADOPT were obtained in obese subjects with type 2 diabetes, and application to lean subjects needs further study. These data imply that the rapid decline in beta cell function in obese subjects does not seem to be explained by the effect of medication. Although the previous and our present study had a cross-sectional design, these consistent findings will foster the conduct of prospective studies to assess the effect of obesity on declining beta cell function in subjects with type 2 diabetes. It has been shown that a modest weight reduction $(\sim 7 \%$, $5-6 \mathrm{~kg}$ ) by lifestyle modification delays the onset of 
type 2 diabetes [18], and a marked weight reduction ( $\sim 60-70 \%$ of excess weight, $\sim 40 \mathrm{~kg}$ ) by bariatric surgery can resolve type 2 diabetes [19]. It will also be of great interest to determine whether treatment of obesity will preserve beta cell function in subjects with type 2 diabetes.

Our linear regression analysis estimated that the fasting and postprandial CPR indices declined at 0.007 and $0.025 /$ year in lean subjects, and at 0.022 and 0.059 /year in obese subjects, respectively. CPR is a well-known marker of beta cell function [20,21]. We have previously reported that fasting and postprandial CPR indices strongly correlated with each other, but the postprandial CPR index was a better predictor of the need for future insulin therapy than the fasting CPR index [9, 12], suggesting that postprandial CPR index reflects beta cell function better than the fasting CPR index. This may be because the postprandial CPR index better reflects potential beta cell functional capacity than does fasting CPR index, due to postprandial glucose load and incretin effects [22]. Of note, our estimates of the rate of decline of postprandial CPR index were close to the previous findings showing a decline in glucagon-stimulated serum CPR level of $0.035 \mathrm{ng} /(\mathrm{mL}$ year) in lean and $0.068 \mathrm{ng} /(\mathrm{mL}$ year) in obese subjects [10]. Our study also showed that postprandial CPR index in obese subjects decreased by $\sim 50 \%$ between newly-diagnosed and long-standing type 2 diabetics, while that in lean subjects decreased by $\sim 35 \%$. As a result, although $\mathrm{BMI}$ is positively correlated with CPR level, there was no significant difference in fasting and postprandial CPR indices between lean and obese subjects more than 10 years after diagnosis. While the difference in urinary CPR level remained significant between lean and obese subjects with long-standing type 2 diabetes, the poorer glycemic control in obese subjects (FPG $146 \pm 27$ vs. $132 \pm 27 \mathrm{mg} / \mathrm{dL}$ in obese and lean subjects, $p=0.003$ ) might affect urinary CPR level. We have also reported that postprandial serum CPR index is a better predictor of subsequent insulin therapy compared to urinary CPR [12], suggesting that serum CPR index is more accurate than urinary CPR as a marker of beta cell function in clinical settings.

Several mechanisms of beta cell dysfunction have been proposed, such as hyperglycemia (glucose toxicity), dyslipidemia (lipotoxicity), inflammation, IAPP, oxidative stress and ER stress [23], all of which could be associated with obesity. The mechanism of obesity-induced beta cell dysfunction needs to be clari- fied in future studies. Since these factors have been shown to not only cause beta cell dysfunction, but also induce beta cell apoptosis, obesity may affect the change in beta cell mass in subjects with type 2 diabetes. Although it has been reported that the CPR to glucose ratio after a glucose load is closely related to fractional beta cell area in humans [24], the assessment of beta cell mass in vivo remains to be established.

There are limitations of our study. First, because our study was a cross-sectional study design, we were not able to confirm a causal relationship between obesity and beta cell dysfunction. A prospective study is warranted. Second, because of our retrospective study design, unknown confounding factors, including trajectories of medications before admission, might have affected our findings. However, the detailed medical information on our study subjects showed a significant increase in the proportion of subjects who received medical therapy and had complications with time after diagnosis, suggesting that our study population reflected the natural history of type 2 diabetes and the existence of apparent selection bias was unlikely. Also, the trajectories of body weight before admission were not available in this study. However, among the subjects whose maximum body weight in their life was available $(n=483)$, there was a strong correlation between the maximum body weight and the weight on admission $(r=0.857, p<0.001)$, suggesting that the definition of obesity based on the weight on admission in this study was appropriate. Nonetheless, the duration of obesity was not available, and should be addressed in a future study. Third, it should be noted that because our study subjects were admitted to hospital because of poor glycemic control, our findings may not reflect outpatients with good glycemic control.

In conclusion, we report that the decline in beta cell function with time after diagnosis of type 2 diabetes was more apparent in obese subjects than in lean subjects. Although this is a cross-sectional analysis and our findings need to be confirmed in a prospective study, our study indicates that treatment of obesity may be an important strategy to preserve beta cell function in patients with type 2 diabetes.

\section{Acknowledgement}

The authors have no conflict of interest. The authors thank Dr. Wendy Gray for editing the manuscript. 


\section{References}

1. Rhodes CJ (2005) Type 2 diabetes-a matter of beta-cell life and death? Science 307: 380-384.

2. Defronzo RA (2009) Banting Lecture. From the triumvirate to the ominous octet: a new paradigm for the treatment of type 2 diabetes mellitus. Diabetes 58: 773795.

3. Butler AE, Janson J, Bonner-Weir S, Ritzel R, Rizza RA, Butler PC (2003) Beta-cell deficit and increased beta-cell apoptosis in humans with type 2 diabetes. Diabetes 52: 102-110.

4. Sakuraba H, Mizukami H, Yagihashi N, Wada R, Hanyu C, Yagihashi S (2002) Reduced beta-cell mass and expression of oxidative stress-related DNA damage in the islet of Japanese Type II diabetic patients. Diabetologia 45: 85-96.

5. Yoon KH, Ko SH, Cho JH, Lee JM, Ahn YB, Song KH, Yoo SJ, Kang MI, Cha BY, Lee KW, Son HY, Kang SK, Kim HS, Lee IK, Bonner-Weir S (2003) Selective betacell loss and alpha-cell expansion in patients with type 2 diabetes mellitus in Korea. J Clin Endocrinol Metab 88: 2300-2308.

6. Rahier J, Guiot Y, Goebbels RM, Sempoux C, Henquin JC (2008) Pancreatic beta-cell mass in European subjects with type 2 diabetes. Diabetes Obes Metab 10 Suppl 4: 32-42.

7. U.K. Prospective Diabetes Study Group (1995) U.K. prospective diabetes study 16 . Overview of 6 years' therapy of type II diabetes: a progressive disease. Diabetes 44: 1249-1258.

8. Koga M, Murai J, Saito H, Kasayama S (2010) Glycated albumin and glycated hemoglobin are influenced differently by endogenous insulin secretion in patients with type 2 diabetes. Diabetes Care 33: 270-272.

9. Saisho Y, Tanaka K, Abe T, Shimada A, Kawai T, Itoh H (2011) Glycated albumin to glycated hemoglobin ratio reflects postprandial glucose excursion and relates to beta cell function in both type 1 and type 2 diabetes. Diabetol Int 2:146-153.

10. Funakoshi S, Fujimoto S, Hamasaki A, Fujiwara H, Fujita Y, Ikeda K, Hamamoto Y, Hosokawa M, Seino Y, Inagaki N (2008) Analysis of factors influencing pancreatic beta-cell function in Japanese patients with type 2 diabetes: association with body mass index and duration of diabetic exposure. Diabetes Res Clin Pract 82: 353-358.

11. Wallace TM, Levy JC, Matthews DR (2004) Use and abuse of HOMA modeling. Diabetes Care 27: 14871495.

12. Saisho Y, Kou K, Tanaka K, Abe T, Kurosawa H, Shimada A, Meguro S, Kawai T, Itoh H (2011) Postprandial serum C-peptide to plasma glucose ratio as a predictor of subsequent insulin treatment in patients with type 2 diabetes. Endocr J 58: 315-322.

13. The Commitee of the Japan Diabetes Society on the Diagnostic Criteria of Diabetes Mellitus (2010) Report of the committee on the classification and diagnostic criteria of diabetes mellitus. J Diabetes Invest 1: 212228.

14. Japan Diabetes Society (2010) The guideline for the treatment of diabetes. Japan Diabetes Society, Tokyo (In Japanese).

15. Matsuo S, Imai E, Horio M, Yasuda Y, Tomita K, Nitta K, Yamagata K, Tomino Y, Yokoyama H, Hishida A (2009) Revised equations for estimated GFR from serum creatinine in Japan. Am J Kidney Dis 53: 982992.

16. Horio $\mathrm{M}$, Imai E, Yasuda $\mathrm{Y}$, Watanabe $\mathrm{T}$, Matsuo $\mathrm{S}$ (2010) Modification of the CKD epidemiology collaboration (CKD-EPI) equation for Japanese: accuracy and use for population estimates. Am J Kidney Dis 56: 32-38.

17. Kahn SE, Haffner SM, Heise MA, Herman WH, Holman RR, Jones NP, Kravitz BG, Lachin JM, O’Neill MC, Zinman B, Viberti G (2006) Glycemic durability of rosiglitazone, metformin, or glyburide monotherapy. $N$ Engl J Med 355: 2427-2443.

18. Knowler WC, Barrett-Connor E, Fowler SE, Hamman RF, Lachin JM, Walker EA, Nathan DM (2002) Reduction in the incidence of type 2 diabetes with lifestyle intervention or metformin. $N$ Engl J Med 346: 393-403.

19. Buchwald H, Avidor Y, Braunwald E, Jensen MD, Pories W, Fahrbach K, Schoelles K (2004) Bariatric surgery: a systematic review and meta-analysis. JAMA 292: 17241737.

20. Tsai EB, Sherry NA, Palmer JP, Herold KC (2006) The rise and fall of insulin secretion in type 1 diabetes mellitus. Diabetologia 49: 261-270.

21. Torn C (2003) C-peptide and autoimmune markers in diabetes. Clin Lab 49: 1-10.

22. Drucker DJ, Nauck MA (2006) The incretin system: glucagon-like peptide-1 receptor agonists and dipeptidyl peptidase- 4 inhibitors in type 2 diabetes. Lancet 368: 1696-1705.

23. Donath MY, Ehses JA, Maedler K, Schumann DM, Ellingsgaard H, Eppler E, Reinecke M (2005) Mechanisms of beta-cell death in type 2 diabetes. Diabetes 54 Supp1 2: S108-113.

24. Meier JJ, Menge BA, Breuer TG, Muller CA, Tannapfel A, Uhl W, Schmidt WE, Schrader H (2009) Functional assessment of pancreatic beta-cell area in humans. Diabetes 58: 1595-1603. 